\title{
INLINE MONITORING OF PHASE TRANSFORMATION IN HOT STRIP MILL*
}

\author{
Frenk van den Berg ${ }^{1}$ \\ Haibing Yang ${ }^{1}$ \\ Jos Mosk ${ }^{2}$ \\ Tony Peyton ${ }^{3}$ \\ Peter Hunt ${ }^{4}$
}

\begin{abstract}
In the manufacturing of steel strip for the automotive sector, the mechanical properties are largely defined by the process conditions in the hot strip mill. In particular the phase transformation, from austenite to ferrite, which takes place during the forced cooling stages on the run out table (ROT) after the finishing mill, governs the microstructure and hence the mechanical properties. In current practice, metallurgical models are used to predict the phase state at each position in the strip. These model predictions are supported by pyrometer measurements along the ROT. Although reliable in the majority of the situations, both measurements and models sometimes have difficulties in providing robust output. In this paper, we present a new type of inline measurement, which directly measures the amount of phase transformed. The instrument is based on a technique known as impedance spectroscopy. As result of a collaboration of different institutes and companies, the equipment is robustly running during several years exclusively in the Hot Strip Mill of Tata Steel in IJmuiden.
\end{abstract}

Keywords: Hot strip mill; Phase transformation; Inline monitoring; Impedance spectroscopy.

1 PhD, Tata Steel Research \& Development, IJmuiden, The Netherlands. frenk.van-denberg@tatasteel.com

2 Ir, Tata Steel Mainland Europe, Hot Strip Mill, IJmuiden, The Netherlands.

3 Professor, University of Manchester, School of Electrical and Electronic Engineering, Manchester, United Kingdom.

4 PhD, Primetals Technologies, Technology Centre, Aviation Park West, Bournemouth International Airport, Christchurch, Dorset, United Kingdom. 


\section{INTRODUCTION}

The microstructure of steel, which determines the technical-mechanical properties, is predominantly defined during the processes in the hot strip mill (HSM). In this plant, steel slabs of typical dimensions $\mathrm{L} \times \mathrm{W} \times \mathrm{H}=12 \mathrm{~m} \times 2 \mathrm{~m} \times 0.22 \mathrm{~m}$ are heated in furnaces to approximately $1200^{\circ} \mathrm{C}$ and in successive steps rolled to a strip of $2-12$ $\mathrm{mm}$ thickness and about $200-1200 \mathrm{~m}$ long. At the end of the ROT the strip is wound up around a coiler at a temperature of about $600^{\circ} \mathrm{C}$.

In combination with the chemical composition, the cooling rate in different sections in the temperature trajectory from $1200^{\circ} \mathrm{C}$ to coiling temperature, as well as the coiling temperature itself, largely determines the microstructure of the steel strip. An important step in this process is the phase transformation from austenite to ferrite which takes place in the dynamic hot rolling process on the ROT in the temperature range $600-800^{\circ} \mathrm{C}$. The exact transformation temperature (range) is determined by the cooling rate and chemical composition.

Although process models are well advanced to predict the progress of the phase transformation in the strip on the ROT, process control is much favoured by a device that can detect the occurrence of the transformation in real-time. For this purpose, the so-called EMspec-sensor has been developed at the University of Manchester (UK) [1] in close collaboration with TATA Steel Research and Development. The multi-frequency impedance analyser, termed EMspec (electromagnetic inspection), exploits the fact that the ferritic phase is ferromagnetic, while the austenitic phase is paramagnetic. This implies that the phase transformation from $\gamma \rightarrow \alpha$ is accompanied by a significant change in (relative) magnetic permeability $\mu_{\mathrm{r}}$ from 1 to a value larger than 100 (typically $200-300$ ). Hence, by probing the value of $\mu \mathrm{r}$, the sensor can detect the $\gamma \rightarrow \alpha$ phase transformation. Because of the general fact that ferromagnetism disappears above the Curie temperature, this detection method is only valid if the transformation takes place below the Curie temperature.

The sensor is positioned about $30 \mathrm{~mm}$ underneath the strip, between the transport rolls, in the ROT of the HSM. In this position, the device is safeguarded against collisions with the strip, in particular during the passage of the head and tail of the strip.

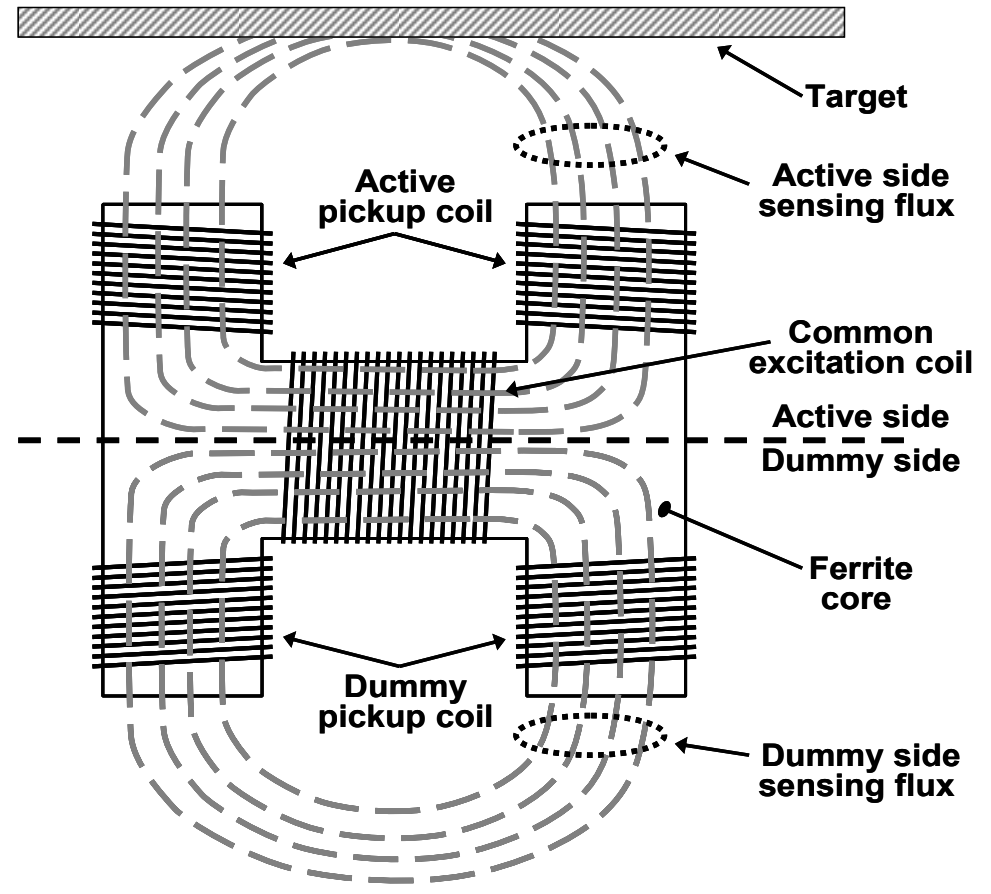

Figure 1. EMspec sensor head, consisting of ferrite yoke, excitation coil and pick-up coils. 


\section{METHODOLOGY}

\subsection{Sensor Details}

The sensor consists of an $\mathrm{H}$-shaped ferrite yoke with a field exciting coil on the central bar, see Figure 1. The vertical legs are equipped with identical pick-up coils. By subtraction of the signal on the bottom pick-up coils ("dummy signal coils") from the signal on the top pick-up coils ("active signal coils"), the device has been made less sensitive to potential noise sources like electromagnetic stray fields and temperature induced changes in the pick-up coils or in the yoke material. The excitation of the EMspec system runs simultaneously at 8 different frequencies in the range $\sim 0.2-24 \mathrm{kHz}$. A digital signal processor (DSP) calculates impedance information based on the fast Fourier transforms of the measured excitation current and induced voltage.

The principle of the EMspec system to sense the relative magnetic permeability $\mu \mathrm{r}$ may best be described by the analogy of the complex impedance of an air-core coil positioned below a metal plate. For this situation, analytical integral expressions exist, as derived in [2]. From these expressions, it can be deduced that the zero crossing frequency $\left(f_{0}\right)$ of the inductance of the coil is linearly related to the materials' magnetic permeability $\mu_{r}$.

From both theoretical modelling and measurement it has been found $[3,4]$ that in the ferrite phase fraction $\left(f_{\alpha}\right)$ domain of $40-100 \%$, the property $\mu_{r}$ is almost linearly related to $f_{\alpha}$. Below $40 \%$ ferrite phase fraction, $\mu_{r}$ is found to be close to 1 . This is attributed to the morphology of the ferritic phase in the partial transformation stage: based on the investigation of micrographs. It appears that for $f_{\alpha}<40 \%$, the ferrite phase consists mainly of isolated particles, while for above $f_{\alpha}>40 \%$, the ferrite particles start to interconnect, effectively providing a path for the magnetic flux.

In the practice of an industrial measurement, preference has been given to the use of a ferrite core to reinforce the magnitude of the magnetic field in order to obtain acceptable signal-to-noise levels in the hostile environment of the hot strip mill. In the system design, we have been keen to obtain a sensor response which has minimal cross-sensitivity to the lift-off, i.e. the distance (known as lift-off) between the sensor and the steel. Evidently, an increase of lift-off results in a decrease of the signal magnitude. However, the phase angle of the complex impedance appears to yield a good discrimination for ferromagnetic phase content [5], while being almost independent of lift-off over the range of interest, as testified by Figure 2 and Figure 3 (Experimentally obtained impedance plot in the complex plane at 8 different frequencies).

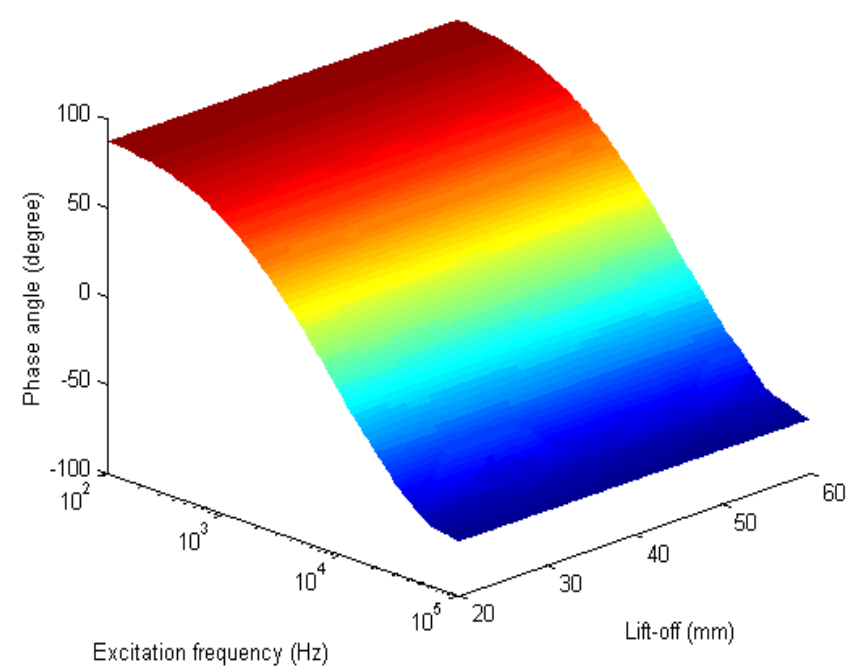

Figure 2. Phase signature of a $2.0 \mathrm{~mm}$ thick ferritic steel plate at different lift-offs, from [5]. 
$100 \%$ ferritic - $1.2 \mathrm{~mm}$ thick

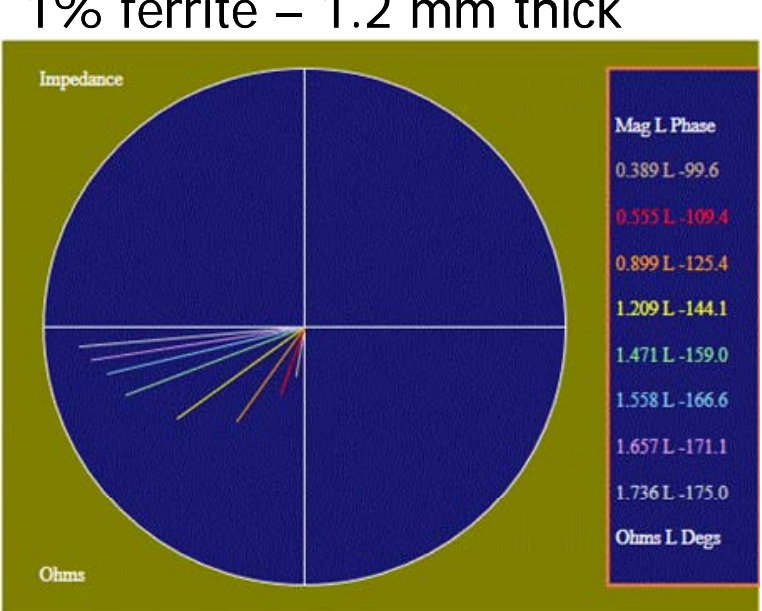

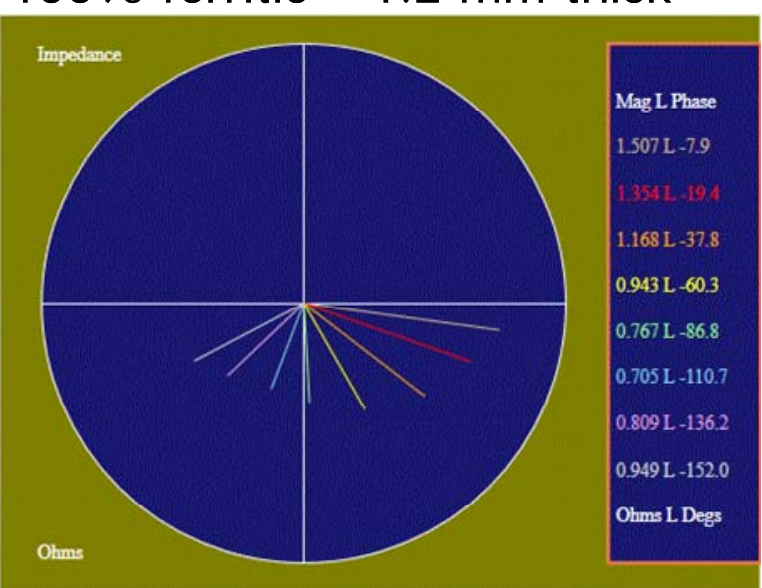

Figure 3. Impedance plane for $1 \%$ and $100 \%$ ferritic steel samples.

\subsection{Sensor Housing and Installation}

The sensor has to be housed very robustly in order to survive in the harsh conditions of the run-out table of the hot strip mill, where the hot strip at $\sim 600-700^{\circ} \mathrm{C}$ passes at speeds up to $20 \mathrm{~m} / \mathrm{s}$. In addition, space constraints are imposed by the narrow gap between the transport rolls of only about $74 \mathrm{~mm}$, in which the sensor has to be mounted.

The sensor housing has to fulfil a series of functions, i.e:

- mechanical protection of the sensor;

- thermal conditioning of the sensor;

- electromagnetic shielding against influences from the production environment;

- electromagnetic transparency towards the strip which has to be sensed.

The limited available space has set important challenges to the mechanical design to combine all the abovementioned functional requirements into a single, compact and robust housing solution.

Figure 4 presents a schematic picture of the result of the design work. The sensor yoke is fixed in a steel housing, which is water-cooled at the sidewalls. A temperature sensor

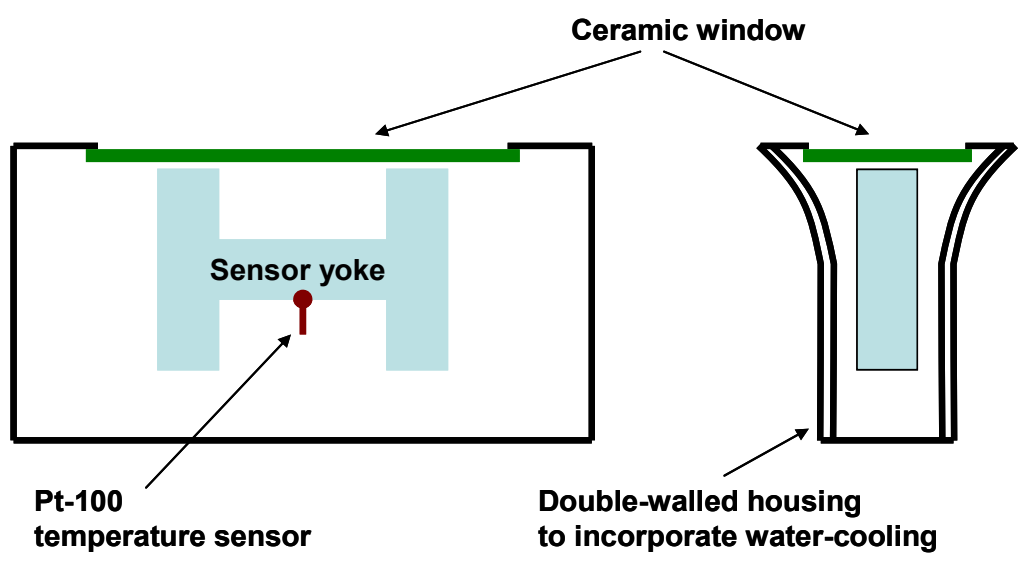

Figure 1. Schematic drawing of the sensor housing; Left: front view; Right: side view.

mounted against the yoke

allows monitoring of the sensor core temperature, to verify if the water flow is properly tuned, in particularly upon start-up of the mill after a maintenance stop. 


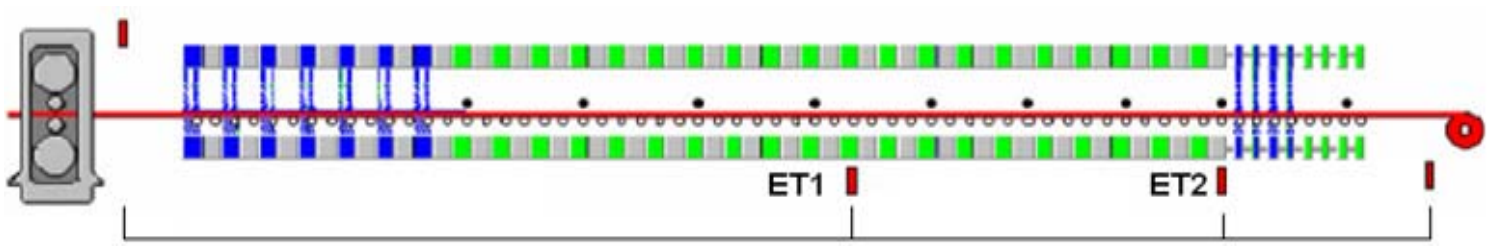

Figure 5. Schematic layout of the run-out table of the Tata Steel HSM \#2 in IJmuiden (The Netherlands). The transformation sensor is installed at position ET1.

The measurement instrument has been installed at the ET1 position in the run-out table (ROT) of the hot strip mill at Tata Steel Europe in IJmuiden, The Netherlands, see Figure 5. At this position, also the strip temperature is measured with a pyrometer system. The combined information of both temperature and microstructure obviously gives a more complete picture of the material state at the point of measurement.

Figure 6 shows a picture of the sensor, positioned in the gap between the transport rolls and mounted on a slider bar. The slider bar allows relatively easy retraction of the device for testing and maintenance purposes. At the left and right side of figure 6 , the nozzle bars are visible for the

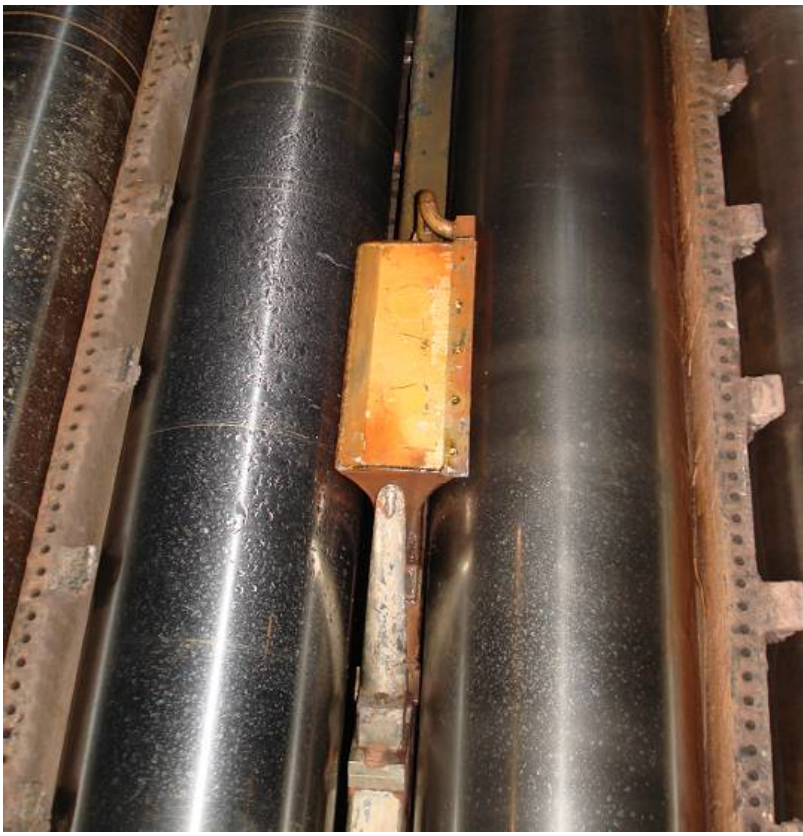

Figure 6. Installation of the sensor in its housing in between the transport rolls of the HSM in IJmuiden, The Netherlands. active cooling of the strip.

The sensor is calibrated in-situ during a maintenance stop, using 2 plate-like objects which correspond to the extremes of the spectrum to be measured, i.e. a purely austenitic plate (representing $0 \%$ transformed) and a purely ferromagnetic object (representing 100\% transformed).

\subsection{Procedure to Infer Phase Information from the Measurement}

From the phase information from the real-time measured induction spectra, the ferrite fraction is determined using the inversed data from measurement models which have been developed at the Universities of Birmingham and Manchester [1,4], and modified by Tata Steel R\&D for inline use at elevated temperatures. Figure 7 shows the employed relationships in the measurement models for a hot-rolled carbon manganese steel at room temperature conditions. The zero-crossing frequency parameter [1] that is derived from the inline measurement is linearly related to the relative magnetic permeability of the strip, and the latter has a unique relationship with a two-phase material which is calculated from common mixed-medium theories. 

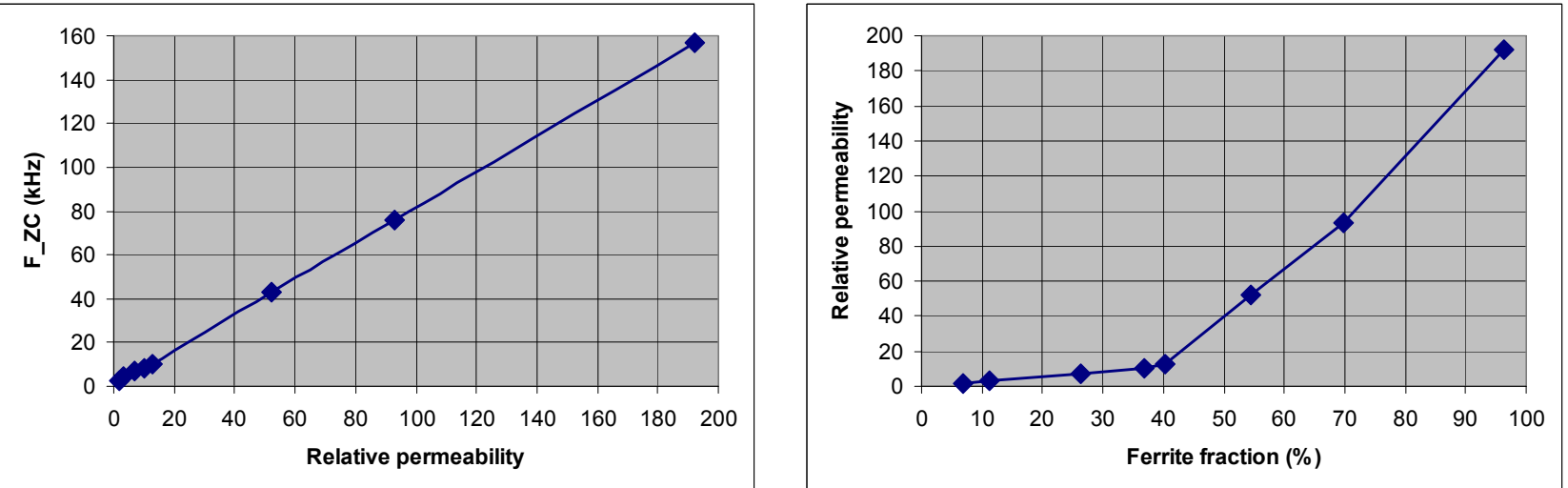

Figure 7. Measurement model to deduce the ferrite fraction from the measurement. Left: relation between induction measurement parameters (F_ZC = zero-crossing frequency) and magnetic permeability; Right: Relation between magnetic permeability and ferrite fraction.

\section{RESULTS FROM THE INLINE PHASE MEASUREMENT}

Figure 8 demonstrates the results of the inline phase measurement, in combination with model predictions [6] (not detailed here). The measurement delivers a value for the fraction transformed at a length resolution of $2 \mathrm{~m}$ or better over the entire coil length. As can be seen from the figure, results are very consistent over the coil length as long as strip tension is applied to keep the strip in a straight pass line.

This unprecedented possibility to sense the phase fraction in-situ and in real-time opens a new horizon for control of the microstructure in the hot strip mill. Improved control opportunities are of particular importance for steels with a more complicated microstructure, like Dual-Phase (DP) and Complex-Phase (CP) steels, because the microstructure of these steels is much more critical to the temperature-time trajectory that the material has experienced.

To illustrate, Figure 9presents the measured phase fraction over the coil length, in combination with the strip temperature at the exit of the finishing mill. The smoothness of the phase fraction curve is remarkable, indicating a small noise and an excellent repeatability of the inline measurement, even in the industrial conditions in the mill. Secondly, the strong (inverse) correlation with the finishing temperature is to be noted. Even the smaller peaks in the temperature curve are (inversely) reproduced in the phase fraction curve. The strong correlation may be explained by the fact that phase transformation during the cooling process is sensitive to the conditions at the entry point of the ROT, which is particularly true for high strength steels. This provides additional evidence that the measurement device is a sensitive tool for phase fraction characterisation. 

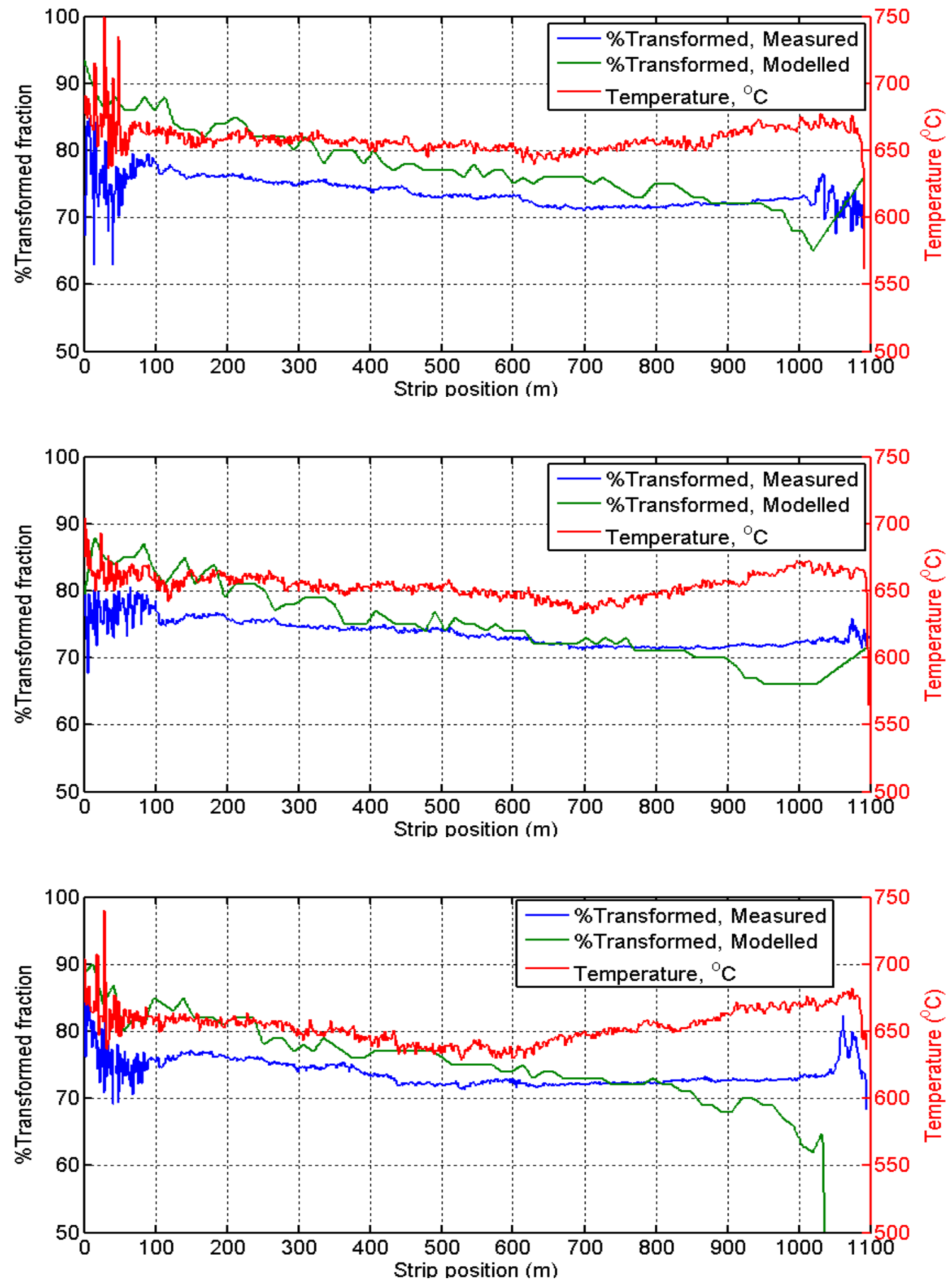

Figure 8. Three plots showing the EMspec output for 3 different coils of the same carbon-manganese grade and the same thickness $(t=2.3 \mathrm{~mm})$, rolled at almost similar process conditions. The head and tail ends of the strip produce noisy results because of lack of strip tension. Predictions from metallurgical modelling seem to over-estimate (or to amplify) trends, while the measurements give very consistent results over strip length and also from one coil to the other. 


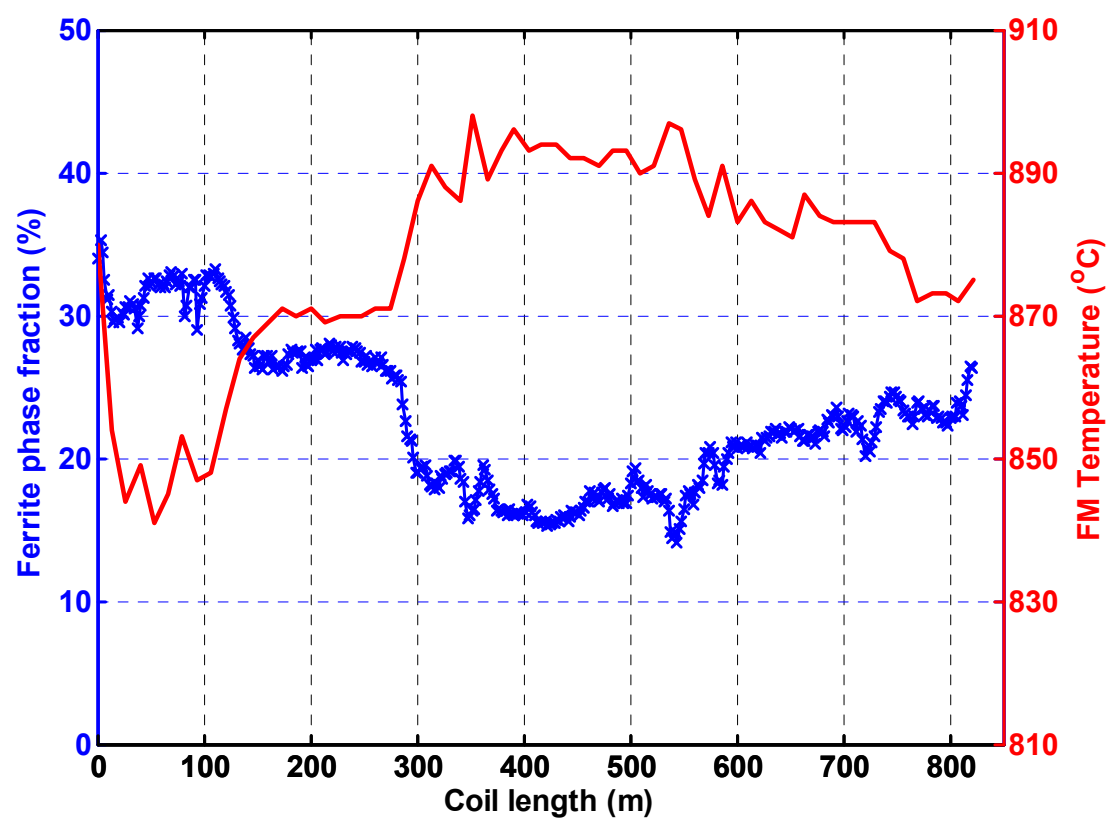

Figure 9. Finishing mill temperature (red) and measured phase fraction (blue) of a DP steel over the coil length.

\section{DISCUSSION}

The inline EMspec instrument is, as far as known to the authors, the only equipment which is capable of measuring the ferrite fraction over the strip length accurately and highly resolved. Other developments, like an electromagnetic sensor developed at the Moscow Institute of Steel and Alloys for Arcelor Mittal [7,8] suffer from lift-off sensitivity, resulting in reduced accuracy and the need for signal averaging which reduces the position resolution.

Other authors [9-11] have proposed and trialled Laser-based Ultrasonics to monitor the microstructure evolution of the strip in the hot strip mill. However, the strongly varying conditions of the steel surface due to scale formation and cooling water hamper the establishment of a reliable and robust laser-based measurement. Additionally, since strong laser pulses are needed, safety issues pose serious obstacles to the industrial application of this technique. Hence we believe that electromagnetic techniques provide a cheaper and more reliable solution to the inline monitoring of phase transformation in the hot strip mill.

\section{OUTLOOK}

The EMspec development has been in the pilot phase at TATA Steel during the past 3 years, where the industrially housed sensor has been installed in the ROT of the HSM at the IJmuiden site in The Netherlands. In these dynamic conditions, device validation, as well as sensitivity studies have been carried out to evaluate the value and robustness of the instrument for process control. 
Recently, Tata Steel has started the industrialisation phase in collaboration with Primetals (a joint venture of Siemens VAI Metals Technologies and Mitsubishi Heavy Industries (MHI) and partners). Here, the sensor system hard- and software have received a major overhaul to ensure high-speed and robust operation, featuring

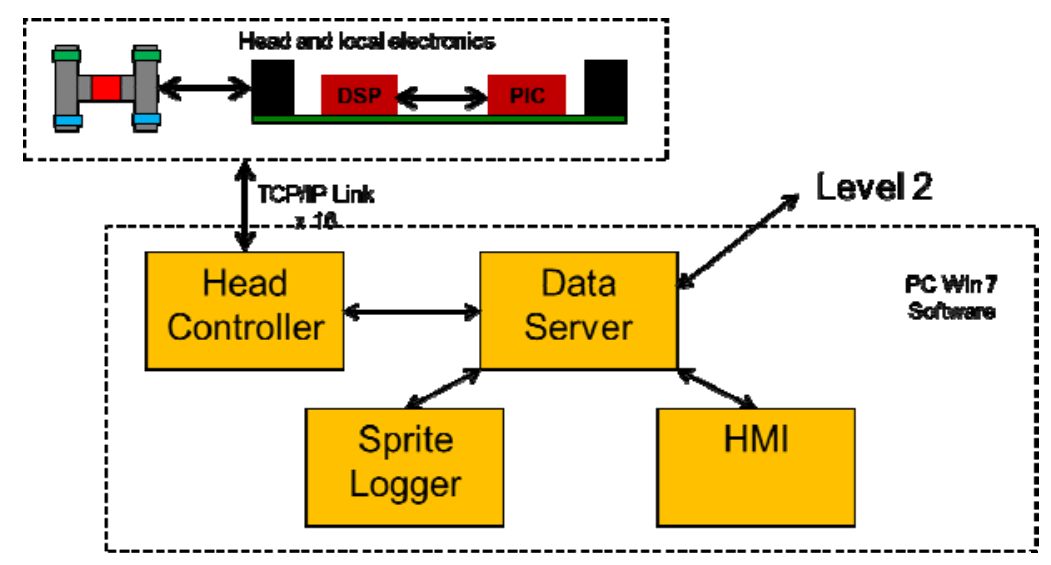

Figure 10. Primetals DAQ System improved sensor condition monitoring and enhanced interaction with the IT infrastructure of the plant in order to obtain accurate

synchronisation across the strip length. Also, the housing has been further optimised to minimize replacement time in case of damage to the device.

The new data acquisition system provides the possibility to process data from multiple measurement devices (up to 16), and uses a server-client structure to communicate and transfer the data from the local digital signal processor unit, via the host PC to the level 1 and 2 systems of the plant. A Human Machine Interface (HMI) provides multiple options for data visualisation, either of real-time data, or of historic data. Details of the various functions are provided in [12].

Within this collaboration, we envisage to install additional sensors along the length of the run-out table. As such, we will create opportunities for characterisation of the transformation rate. Moreover, we will enlarge the portfolio of steel grades which can be sensed, as different steel grades transform at different positions on the ROT. This approach strengthens even further the leading position that Tata Steel has in the sensing and control of microstructure in the hot rolling stage of steel manufacturing, and ensures steel deliveries to its customers that meet the highest quality standards.

\section{REFERENCES}

1 Yin W, Hao XJ, Peyton AJ, Strongwood M, Davis CL: "Measurement of permeability and ferrite/austenite phase fraction using a multi-frequency electromagnetic sensor," NDT\&E Int., Vol.42 (2009) pp.64-68.

2 Dodd CV, Deeds WE: "Analytical solutions to eddy-current probe-coil problem", J Appl Phys - Vol.39 (1968) pp 2829-2839.

3 Yin W, Hao XJ, Peyton AJ, Strongwood M, Davis CL, "Exploring the relationship between ferrite fraction and morphology and the electromagnetic properties of steel", Journal of Materials Science -Vol. 42 (2007) pp 6854-6861.

4 Hao XJ, Yin W, Strongwood M, Peyton AJ, Morris PF, Davis CL: "Modelling the electromagnetic response of two-phase steel microstructures", NDT\&E International Vol. 43 (2010) pp 305-315.

5 Yin W, Binns R, Dickinson SJ, Davis CL, Peyton AJ: " Analysis of the Liftoff Effect of Phase Spectra for Eddy Current Sensors", IEEE Trans Instrum Meas, 56, 2775-2781 (2007)

6 Zhu W, Yang H, Luinenburg A, Berg FD van den, Dickinson S; Yin W, Peyton AJ: The development and deployment of an on-line multi-frequency electromagnetic system to 
monitor steel hot transformation on the run-out table of a hot strip mill", Ironmaking and Steelmaking 2014 Vol41 No.9 PP685-693

7 Kaputkina, Shchetinin, Marmulev, Poliak and Herman : "Nonuniform structure and properties in Hot-rolled Low-Carbon Steel coils", Steel in Translation, Vol. 43 (2013) pp561-565.

8 Marmulev, Herman, Turon, Poliak and Kaputkina: "Online electromagnetic monitoring of austenite fransformation in hot strip rolling and its application to process optimisation", Revue de Métallurgie Vol. 110 (2013) pp205-213

9 Dubois M. Bussiere JF: "Rapid microstructure assessment in rolled steel products using laser ultrasonics", in Nondestructive Characterisation of Materials VIII, Plenum Press, New York, 1998 pp329-333

10 Hutchinson B, Moss B, Smith A, Astill A, Scruby C, Engberg G, Björklund J: "Online characterisation of steel structures in hot strip mill using laser ultrasonic measurements", Ironmaking and Steelmaking 2002 Vol 29 No 1 pp77-80

11 Hedin A, Lindh-Ulmgren E, Borg, M, Hutchinson B, Carlson L: "Laser-Ultrasonics for Microstructure Characterisation On-line in Steel Processing", Proceedings 1st Int Symp on Laser Ultrasonics, July 16-18 2008, Montreal, Canada

12 Hunt P, Sherman P, Peyton AJ, Berg, FD van den, Yang, H: "The Real Time Transformation Control at Hot Strip Mill", paper to be presented on METEC 2015, 16 19 June 2015, Düsseldorf Germany. 